\title{
Ocorrência de Babesia spp. em amostras hematológicas em vacas Nelore e a importância de sua profilaxia na Cidade de Porto Velho - Rondônia
}

Occurrence of Babesia spp. in hematological samples in Nelore cows and the importance of its prophylaxis in the City of Porto Velho - Rondônia

Ocurrencia de Babesia spp. en muestras hematológicas en vacas Nelore y la importancia de su profilaxis en la Ciudad de Porto Velho - Rondônia

Resumo

A babesiose é causada por um protozoário do gênero Babesia spp, que parasita as células sanguíneas, a qual é transmitida através do ectoparasita Rhipicephalus microplus. É uma patologia com grande importância econômica. O objetivo desse trabalho foi analisar o perfil hematológico de 30 vacas Nelore, para diagnóstico de babesiose bovina, estabelecer sua prevalência e discutir sobre a importância dos cuidados profiláticos para tal enfermidade. Os resultados demonstraram que as análises para babesia spp foram negativas, mesmo com a presença do carrapato, discutindo assim hipóteses para tal ocorrido, como resistência do hospedeiro ao hemoparasita, falhas no manejo profilático ou resistência do ectoparasita a princípios ativos.

Palavras-chave: Parasitos; Hematologia; Bovinos; Prevenção; Manejo.

\begin{abstract}
Babesiosis is caused by a protozoan of the genus Babesia spp, which parasitizes blood cells, which is transmitted through the Rhipicephalus microplus ectoparasite. It is a pathology of great economic importance. The aim of this study was to analyze the hematological profile of 30 Nellore cows for diagnosis of bovine babesiosis, to establish its prevalence and to discuss the importance of prophylactic care for such disease. The results showed that the analyzes for babesia spp were negative even with the presence of tick, thus discussing hypotheses such as host resistance to hemoparasite, prophylactic management failures or ectoparasite resistance to active principles.
\end{abstract}

Keywords: Parasite; Hematology; Cattle; Prevention; Management. 


\section{Resumen}

La babesiosis es causada por un protozoo del género Babesia spp, que parasita las células sanguíneas, que se transmite a través del ectoparásito Rhipicephalus microplus. Es una patología de gran importancia económica. El objetivo de este trabajo fue analizar el perfil hematológico de 30 vacas Nellore, para el diagnóstico de babesiosis bovina, establecer su prevalencia y discutir la importancia de los cuidados profilácticos para esta enfermedad. Los resultados mostraron que los análisis para babesia spp fueron negativos, incluso con la presencia de la garrapata, por lo que se discutieron hipótesis para tal ocurrencia, como resistencia del huésped al hemoparásito, fallas en el manejo profiláctico o resistencia del ectoparásito a principios activos.

Palabras clave: Parásitos; Hematología; Ganado; Prevención; Gestión.

\section{Introdução}

A babesiose é causada por um protozoário do gênero Babesia spp, que parasita as células sanguíneas, a qual é transmitida através do ectoparasita Rhipicephalus microplus. No mundo, existem oito espécies que podem infectar a espécie bovina (Uilenberg, 2006), mas somente a B. bigemina e B. bovis foram encontradas no Brasil (Osaki et al. 2002).

É uma patologia cosmopolita, com grande importância econômica, principalmente em regiões tropicais e subtropicais (Munoz et al. 2008; Piau Júnior et al. 2013). Esta distribuição anda juntamente com a disseminação do vetor, sendo a taxa de infecção deste diretamente proporcional com a população elevada de carrapatos, que por sua vez é atraída pelas condições ideias de clima (Guglielmone, 1995).

A tristeza parasitária bovina (TPB) está entre as principais patologias que acometem bovinos, principalmente os de leite, tal complexo é causado pelos agentes Babesia bovis, Babesia bigemina e Anaplasma marginale, resultando em perdas econômicas significativas no rebanho, pois possui elevada morbidade e mortalidade animal, principalmente em bezerros, pois além da queda na produção é acompanhado de perda de peso, gastos com tratamento e controle (Gonçalves, 2000; Grisi, et al. 2002; Barros, et al. 2005). Por estes fatores, a vacinação de bezerros em seu primeiro ano de vida aparenta ser uma alternativa afim de evitar possíveis surtos da tristeza parasitária bovina (Costa et al. 2018).

A Babesia bovis é transmitida pelas larvas dos carrapatos, enquanto os estágios de ninfas e adultos transmitem a $B$. bigemina. A epidemiologia da babesiose bovina se dá em áreas livres e de estabilidade enzoótica, as quais apresentam condições climáticas favoráveis a presença e multiplicação dos carrapatos (Kessler et al. 1983; Folly et al. 2009; Trindade, et al. 2011). O que já não ocorre em locais onde o clima se apresenta mais desfavorável, como na região do nordeste do brasileiro, onde o clima é mais quente e a babesia sp. ocorre sob a forma de instabilidade enzoótica (Santos et al. 2017).

Em locais de clima tropical e subtropical, a babesiose apresenta estabilidade, normalmente os bezerros são protegidos por anticorpos maternos através do colostro (Kessler et al. 1983; Madruga et al. 1984). Porém, os animais que não possuíram contato com o patógeno nos primeiros meses de vida apresentam mais susceptibilidade para a patologia (Madruga et al. 1984).

A B. bigemina parasita principalmente as hemácias da circulação periférica, enquanto a B. bovis tem tropismo acentuado pela circulação de órgãos viscerais e centrais, estando presente em capilares de órgãos centrais como cérebro, cerebelo, meninges e nas vísceras como rins, baço, fígado, coração e pulmão (Massard \& Freire, 1985). Durante a infecção aguda o animal pode apresentar quadro de anemia branda, palidez de mucosas, febre, sialorreia, depressão, distúrbios neurológicos, tremores, hipertermia, apatia, taquipneia, hemoglobinúria, icterícia, entre outros sinais (Santos et al. 1998; Soares et al. 2000).

O diagnóstico da babesiose pode ser realizado por meio do clínico-patológico, através do achado de parasitos pelo exame de esfregaços sanguíneos ou de tecidos frescos (Callow \& McGavin, 1963). Contudo, existem outras técnicas que podem ser aplicadas para o diagnóstico, como o exame histopatológico, que tem uma frequência alta de diagnósticos sugestivos (Silva et al. 2018). 
O objetivo desse trabalho foi analisar o perfil hematológico de vacas Nelore de uma Fazenda Agropecuária localizada na cidade de Porto Velho - RO, para possível diagnóstico de babesiose bovina e estabelecer a prevalência desta em vacas através da análise de perfil hematológico, esfregaço sanguíneo juntamente com os sinais clínicos de cada animal e discutir sobre a importância dos cuidados profiláticos para tal enfermidade.

\section{Material e Métodos}

O experimento teve como objetivo avaliar, de forma qualitativa, a presença de uma possível infestação por Babesia spp., sendo conduzido em uma fazenda agropecuária do município de Porto Velho, no estado de Rondônia. Foram utilizadas 30 vacas Nelore, criadas sob as mesmas circunstâncias de manejo nutricional, sanitário e ambiental.

Os animais eram mantidos em pastagem Brachiaria, sob manejo de pastejo rotacionado, e suplementados com sal mineral. São realizados cuidados profiláticos com fármacos para controle de ectoparasitas em todo o rebanho. Porém, os animais ainda apresentavam presença de carrapatos.

O sangue foi coletado através da veia coccígea, foram utilizadas agulhas para coleta de sangue a vácuo 25 x 0,8 Mm 21 $\mathrm{g}$ juntamente com adaptador padrão de agulha, e as amostras foram diretamente adicionadas em tubo com ácido etileno diaminotetracético (EDTA) K3, 4ml, tampa roxa.

As amostras foram homogeneizadas manualmente e acondicionadas imediatamente em caixa térmica com gelox até sua chegada ao Laboratório de Patologia Clínica, onde em um prazo de 24 horas tinha-se o hemograma realizado através do analisador hematológico Poch 100iv Diff, onde realiza suas análises de RBC (eritrócitos), HCT (hematócrito), PLT (plaquetas) por método de detecção por corrente direta com foco hidrodinâmico, que previne a recirculação e consequentemente a coincidências de células. O WBC (leucócitos), HGB (hemoglobina) por método de detecção por corrente direta e método de hemoglobina livre de cianeto. O equipamento inclui também a contagem diferencial de 3 partes para leucócitos (linfócitos, eosinófilos e células mistas (Roche, 2019). O hemograma que analisa as células sanguíneas dos animais, as quais fazem parte da série branca e vermelha, contagem de plaquetas, reticulócitos e índices hematológicos (Kantek et al. 2005).

Logo, foi realizada varredura em esfregaço sanguíneo com microscópio para localização de babesia spp no interior das células.

Após a leitura dos perfis hematológicos e análise dos esfregaços sanguíneos, os resultados foram associados aos sinais clínicos coletados no campo, em seguida foi estabelecido o diagnóstico positivo ou negativo para o hemoparasita.

A coleta das amostras sanguíneas e preenchimento de prontuário com sinais clínicos de vacas Nelore na fazenda Agropecuária foram realizadas no mês de setembro de 2019.

\section{Resultados e Discussão}

Na ocasião da coleta de amostras sanguíneas, foram realizados exames físicos, e observação da presença de ectoparasitas. Dos 30 animais manejados cerca de $90 \%$ apresentaram presença de carrapatos. Porém, todos os bovinos não apresentaram sinais clínicos característicos de babesiose.

$\mathrm{Na}$ varredura das lâminas com esfregaço sanguíneo, não foram localizados parasitas intracelulares de babesia spp, dando ênfase assim na confirmação negativa da patologia.

Ao avaliar os hemogramas, $100 \%$ dos animais apresentaram valores dentro da referência para a espécie conforme Tab. 1, a qual representa a média dos resultados, seguido de máxima e mínima dos exames. 
Tabela 1 - Valores médios do eritrograma e leucograma de 30 vacas Nelore na pesquisa de babesia spp em Porto Velho - RO.

\begin{tabular}{lccc}
\hline & Média & Máximo & Mínimo \\
\hline Hemácias & 9,855 & 12,24 & 7,92 \\
Hemoglobina & 11,15 & 12,5 & 8,9 \\
Hematócrito & 35,35 & 41,1 & 26,9 \\
V.C.M & 35,3 & 40,8 & 32,7 \\
H.C.M & 11,05 & 13,5 & 10 \\
C.H.C.M & 31,5 & 33,2 & 29,7 \\
Leucócito & 13,4 & 19,3 & 11,1 \\
Neutrófilos & 4,77 & 9,9 & 2,6 \\
Linfócitos & 8,5 & 12,7 & 7,1 \\
Plaquetas & 415 & 693 & 43 \\
\hline
\end{tabular}

Fonte: Autores.

O fato de os animais apresentarem carrapatos, mas não apresentarem a patologia, pode se dar pela hipótese de terem imunidade contra o parasita, adquirida ainda jovens. Segundo Kikugawa (2009), os bovinos que passam por infecção natural com várias espécies de babesia adquirem forte imunidade. Uma elevada taxa de infecção acontece nos bovinos na idade de seis a doze meses, e é atípica a infecção nos animais com mais de cinco anos de idade.

Kikugawa (2009) ainda destaca que o bovino nativo das regiões dificilmente é acometido, por conta da resistência natural dos gados jovens e da imunidade passiva adquirida via colostro, originadas de vacas imunes. Quando a patologia ocorre nesses bovinos é decorrente de algum estresse, como o parto, doença intercorrente, baixa de imunidade, ou quando existirem infecções com diferentes parasitas ao mesmo tempo, como na tristeza parasitária.

Assim como Santos (2019) indica, o manejador do gado realizava cuidados profiláticos dos animais, com medicamentos para controle de ectoparasitas e rotação de pastagens. Da mesma forma, Brito (2007) relata que deve haver um descanso de pelo menos 30 dias para a pastagem, afim de o capim recuperar, bem como auxiliar no controle dos vetores da Babesia sp. Também há a hipótese de a quantidade infectante ser insuficiente para causar alterações fisiológicas no animal, demonstrando valores do hemograma dentro do normal. Com isso, é possível destacar a importância da profilaxia para controle de parasitas, onde está pode ser realizada tanto no animal quanto no ambiente.

Conforme Embrapa (2009), pode ser realizado rotação de pastagens para o controle do carrapato fora do animal, introdução de pastagens com poder de repelência e ação letal ao carrapato, dentre outros métodos. A rotação de pastagens é realizada com a retirada dos bovinos do piquete até que todas, maioria das larvas ou todas, sejam eliminadas por causas naturais. 
É indicado aproximadamente 40 dias na primavera/verão e 60 dias no outono/inverno para descanso do pasto. Algumas forrageiras possuem influência na sobrevivência das larvas nas pastagens com a formação de um microambiente aos quais podem agir repelindo as larvas, ou matando-as, as forragens que realizam tal tarefa são capim-gordura, Andropogon, o capim-elefante, Stylosanthes e outras (Embrapa, 2009)

Já Martins (2004), destaca que para controle no animal os endectocidas administrados em determinadas épocas do ano, possui responsividade de um esquema estratégico de controle, como exemplo, uma administração de ivermectina 3,15\% possui resultado similar à três tratamentos com banhos carrapaticidas a intervalos de 21 dias. Conforme a época do ano em que outro protocolo com o mesmo fármaco seja utilizado, a população anual do ectoparasita pode ser controlada estrategicamente dessa maneira, com o uso de Endectocida L. A. em setembro/outubro, repetindo o tratamento em março/abril.

A Embrapa (2009) descreve que a apropriação de uma estratégica de controle do carrapato, com carrapaticidas convencionais ou endectocidas, pode influenciar na geração posterior, afetando a presença de carrapatos que normalmente acometem os bezerros. Assim como Madruga et al. (1984) relata, mesmo com a carga parasitária podendo ser pequena, os bezerros que não recebem a inoculação ativa e não desenvolverem imunidade essencial, desenvolvendo sinais clínicos da patologia ao entrarem em contato com carrapatos infectados.

Rocha et. al (2006) descreve que a ocorrência da resistência não acontece somente ao fato do uso regular do carrapaticida, mas também ao manejo errôneo realizado para o controle do ectoparasita. Além dos fatos relacionados ao manejo que podem influenciar o desenvolvimento rápido da resistência, também pode se dar por conta do intervalo entre os tratamentos contra o ectoparasita, a própria aplicação errada do produto e a insciência, por parte dos produtores, a respeito do ciclo do carrapato e dos grupos carrapaticidas utilizados.

É de suma importância a atenção e cuidado ao realizar o controle e profilaxia dos carrapatos no rebanho. No estudo relatado, o criador utilizava produtos para controle de carrapatos nos bovinos. Porém, ainda foi observado carrapatos em $90 \%$ dos animais separados para o estudo, indicando alguma falha no programa de controle estabelecido para a propriedade, podendo existir a hipótese de resistência do ectoparasita ao princípio ativo utilizado.

\section{Conclusão}

Conclui-se que de fato a profilaxia dos rebanhos não pode ser negligenciada, uma vez que parasitas hematológicos diminuem consideravelmente a produção dos animais, agregando percas econômicas para o produtor, pois estas patologias possuem alta morbidade.

No estudo realizado após pesquisa em um rebanho que recebe cuidados com o pastejo rotacionado e controle de ectoparasitas com produtos especializados, a ocorrência da babesiose se demonstrou zero, porém, havia presença de carrapatos nos bovinos analisados, podendo este fator ser ligado a hipóteses de falhas no manejo profilático ou resistência dos carrapatos ao princípio ativo utilizado.

O resultado negativo para babesia spp, mesmo com a presença de ectoparasitas também pode - se trabalhar com a hipótese de os animais serem imunes ao parasito, adquirindo está ainda quando bezerros.

\section{Considerações Finais}

Na pecuária tanto de corte quanto de leite, nos cuidados de manejo, desde o nascimento até a fase adulta é indicado o controle e profilaxia de ectoparasitas em geral, esses, além das percas econômicas diminuem acentuadamente o bem estar animal, 
visto que os fatores produtivos aumentam quando os animais estão em equilíbrio com o bem estar, sendo bem alimentados, manejados com calma, e realizados manejos preventivos a patologias.

É importante a orientação e supervisão de um médico veterinário na propriedade, pois este possui conhecimento aprofundado da fisiologia animal, farmacologia animal, patologias e controle de ectoparasitas, oferecendo qualidade de vida ao animal e lucro ao produtor rural.

\section{Referências}

Barros, S. L. et al. (2005). Levantamento sorológico de anticorpos de Babesia bovis, Babesia bigemina e Anaplasma marginale em bovinos da região semi-árida do estado da Bahia, por meio de ensaios imunoenzimáticos. Memórias do Instituto Oswaldo Cruz, 100(6): 513-517.

Costa, V. M. M. et al. (2018). Incidência de Anaplasma marginale, Babesia bigemina e Babesia bovis em bezerros no semiárido paraibano. Pesq. Vet. Bras. 38(4): 605-612.

Embrapa (2009). Publicações: Gado de corte divulga, controle do carrapato do boi; Artigos técnicos. (publicado em agosto 1998). http://www.cnpgc.embrapa.br/publicacoes/divulga/GCD31.html, (Acesso em: 08/06/2009).

Folly, M. M. et al. (2009). Ocorrência de Babesia sp. em bezerros mestiços por meio de testes sorológicos, em Campos dos Goyatacazes, RJ, Brasil. Revista Brasileira de Saúde e Produção Animal, 10(1): 44-51.

Garcia-Navarro, C. E. K. (2005). Manual de Hematologia Veterinária. 2ed. São Paulo: Varela, 206 p.

Gonçalves, P. M. (2000). Epidemiologia e controle da tristeza parasitária bovina na região sudeste do Brasil. Ciência Rural, $30(1)$ : $187-194$.

Grisi, L. et al. (2002). Impacto econômico das principais ectoparasitoses em bovinos no Brasil. A Hora Veterinária, 21(125): 8-10.

Guglielmone, A. A. (1995). Epidemiology of babesiosis and anaplasmosis in South and Central America. Veterinary Parasitology, 57(1-3): 109-119.

Kikugawa, M. M. (2009). Tristeza Parasitária Bovina, 2009. 41 pag. Trabalho de Conclusão de Curso (TCC), graduação em Medicina Veterinária - Faculdades Metropolitanas Unidas (FMU), São Paulo - SP.

Madruga, C. R. et al. (1984). Níveis de anticorpos anti-Babesia bigemina e Babesia bovis em bezerros da raça Nelore, Ibagé e cruzamento de Nelore. Pesquisa Agropecuária Brasileira, 19(9): 1163-1168.

Martins, J. R. (2004). De olho na babesiose. Revista Cultivar Bovinos, n.3.

Massard, C. L. \& Freire, R. B. (1985). Etiologia, manifestações e diagnóstico das babesioses bovinas no Brasil. A Hora Veterinária, 4(23): 53-56.

Osaki, S. C. et al. (2002). Ocorrência de anticorpos anti Babesia bovis e estudo sobre a infecção natural em bovinos da raça nelore, na região de Umuarama, Paraná, Brasil. Revista Brasileira de Parasitologia Veterinária, 11(2): 77-83.

Piau Júnior, R. et al. (2013). Levantamento da prevalência da babesiose bovina no município de Umuarama, Paraná, Brasil. Arq. Ciênc. Vet. Zool. 16(1): 25-29.

Rocha, C. M. B. M., Oliveira, P. R. \& Leite, R. C. (2006). Percepção dos produtores de leite do município de Passos, MG, sobre o carrapato Boophilus microplus (Acari: Ixodidae), 2001. Ciência Rural, 36(4): 1235- 1242.

Roche. pocH-100iV Diff. (2019). O Analisador Hematológico da sua Clínica Veterinária. São Paulo, SP, Brasil. Dísponivel em: <http://www.medicane.com.br/Especificacoes/Veterinaria/folder_pochvet_2011_BAIXA.pdf .

Santos, G. B. (2017). Tristeza Parasitária em bovinos do semiárido pernambucano. Pesq. Vet. Bras. 37(1):1-7.

Santos, J. B. (2019). Efeito da rotação de pastagens sobre a infestação de Rhipicephalus microplus Parasitando bovinos (Bos taurus). 44f. Tese (Dissertação na área de Saúde Animal, Tecnologia e Segurança de alimentos).

Santos, T. R. B. et al. (1998). Transmissão transovariana de Babesia bigemina, (Smith \& Kilborne, 1893) por partenóginas de Boophilus microplus (Canestrini, 1887). Revista Brasileira de Parasitologia Veterinária, 7(1): 7-10.

Silva, T. M. et al. (2018). Caracterização histoquímica no diagnóstico da babesiose bovina por Babesia bovis. Pesq. Vet. Bras. 38(4): 649-658.

Trindade, H. I., Almeida, K. S. \& Freitas, F. L. C. (2011). Tristeza parasitária bovina - revisão de literatura. Revista Científica Eletrônica de Medicina Veterinária, 16.

Uilenberg, G. (2006). Babesia - A historical overview. Veterinary Parasitology, 138(1-2): 3-10. 